\title{
DISMINUCION DEL COSTO DEL CULTIVO DE M. tuberculosis A PARTIR DE ESPUTO
}

\author{
LUIS CARLOS OROZCO VARGAS*, ESNEDA GIRALDO DE BLANCO**, CLARA INES LEON FRANCO**, \\ MARTHA INIRIDA GUERRERO**
}

\section{INTRODUCCION}

La metodología fundamental del diagnóstico de la tuberculosis pulmonar es la baciloscopia de esputo. El cultivo es utilizado en pacientes con baciloscopia de esputo seriada negativa como ayuda en el diagnóstico; además, el cultivo es muy útil en las formas extrapulmonares y algunas paucibacilares pulmonares como las infantiles (1).

Nuestros trabajos anteriores muestran claramente que la técnica del escobillón en el medio de Ogawa, modificado por kudoh (2) es muy sencilla y que nuestras modificaciones (3-4) lo hacen más simple y permiten que el procedimiento del cultivo tenga una mayor cobertura.

Estos hechos han aumentado la demanda de tubos en los laboratorios regionales para la preparación y distribución de medios de cultivo hacia los diferentes niveles de los Servicios Seccionales de Salud.

Debido a que los tubos tapa rosca son de difícil consecución y de costo elevado, se realizó este estudio para comparar dicho tubo y un tubo corriente con tapón de caucho, en el diagnóstico de la tuberculosis pulmonar, por cultivo de esputo.

\section{MATERIALES Y METODOS}

Se procesaron 240 esputos de sintomáticos respiratorios, a cada esputo se le adicionó una cantidad igual de fosfato trisódico (FTS) 4.3\% (10 g Na3PO4. 12 $\mathrm{H}_{2} \mathrm{O}$ en $100 \mathrm{ml}$ de A.D.) y después de 24 horas de realizada la mezcla se dividió en dos alícuotas. Cada una de esta fue procesada por el método del escobillón (1) en medio de Ogawa Kudoh (O-K), una en dos tubos tapa rosca y otra en dos tubos tapón de caucho, e incubados a $37^{\circ} \mathrm{C}$. durante 8 semanas. Para el análisis estadístico se utilizó el test de McNemar (5).

\section{RESULTADOS}

De los 240 esputos procesados, 33 fueron positivos en los tubos tapa rosca y 31 en los tubos con tapón de caucho (ver tabla 1).

La comparación de los resultados por el test de McNemar dió un $\mathrm{X}^{2} 0.125$ p $0.7>0.9$ lo que no permite rechazar la hipótesis nula de no diferencia entre los dos procedimientos.

TABLA 1

COMPARACION DE CULTIVO DE $M$. tuberculosis EN TUBO TAPA ROSCA Y TUBOTAPON DE CAUCHO

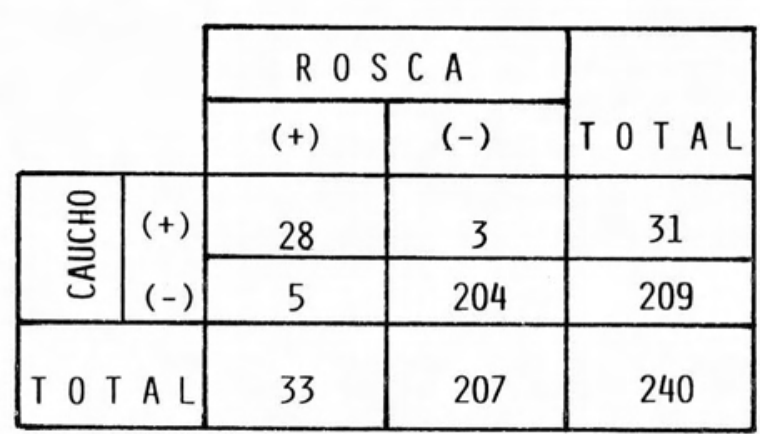

\footnotetext{
* Jefe del Grupo de Micobacterias del Instituto Nacional de Salud. Bogotá.

**Bacteriólogas Grupo de Micobacterias, Instituto Nacional de Salud.

Reimpresós: solicitar a Luis Carlos Orozco Vargas, A.A. 78091 CUAN, Bogotá.
} 


\section{DISCUSION}

Aunque algunos informes (6) abrían la posibilidad de que el caucho inhibiera el crecimiento del $M$. tuberculosis, el presente trabajo con la metodología utilizada, no ha confirmado dicha posibilidad.

La práctica del cultivo de esputo en sintomáticos respiratorios, como ayuda diagnóstica en los programas de control de la tuberculosis, permite aumentar la cobertura diagnóstica de la enfermedad y colabora en el diagnóstico diferencial de los consultantes sintomáticos respiratorios, a los servicios de salud.

Si esta ayuda de laboratorio es lo suficientemente sencilla y económica, se cumple con los postulados de las estrategias para la atención primaria en salud (7).

La simplificación del procedimiento del cultivo de esputo por el método del escobillón (2-3), la posibilidad de realizarlo en centros de salud con recursos mínimos (4) y el presente trabajo que disminuye costos sin disminuir la capacidad diagnóstica del método, permite pensar en utilizar el cultivo de esputo no sólo como ayuda de diagnóstico diferencial, sino como un proceso de rutina dentro del Programa de Control de la Tuberculosis en su componente de diagnóstico de la enfermedad en sintomáticos respiratorios, en aque- llas localidades donde el porcentaje de positividad de la baciloscopia sea bajo $(<4 \%)$ y se haya conseguido una buena regularidad $(>90 \%)$ en la ingesta de la droga por parte de los pacientes.

\section{BIBLIOGRAFIA}

1. Orozco LC, Matyas R. Tuberculosis. Medicina Interna, editado por Fernando Chalem, Jaime Campos, Jorge Enrique Escandón y Roberto Esguerra, Editorial Norma, 1985; cap. 66: 229.

2. Orozco LC, Ramos O de, León Cl, Blanco E de, Moreno Al de. El cultivo de esputo para el diagnóstico de la tuberculosis pulmonar, Biomédica, 1985; 5: 24.

3. Orozco LC, Ramos O de, León $\mathrm{Cl}$, Blanco E de, Moreno, Al de. Una modificación al método de Kudoh para el cultivo de M. tuberculosis. Biomédica, 1985; 5: 86.

4. Orozco LC, León $\mathrm{Cl}$, Bernal M. El diagnóstico de la tuberculosis pulmonar por cultivo de esputo en unidades de salud con recursos mínimos, Biomédica 1987; 7: 35.

5. Hoffmman JIE. The incorrect use of chi-spuare analysis for paired data. Clin Exp Immunol. 1976; 24: 227.

6. Allen BW. Inhibitory effect of rubber on the growth of $M$. tuberculosis. Tubercle 1980; 61: 91.

7. Programa general de trabajo para el período 1984-1989, Ginebra OMS p. 112-113 (Serie Salud para todos No. 8), 1982. 